\title{
THERMAL DRYING TECHNOLOGIES: NEW DEVELOPMENTS AND FUTURE R\&D POTENTIAL
}

\author{
Mujumdar A.S.* and Wu Z.H. \\ *Author for correspondence \\ Department of Mechanical Engineering and Engineering Science Program, \\ National University of Singapore, \\ Singapore, 117575 \\ E-mail: mepasm@nus.edu.sg; website: http://serve.me.nus.edu.sg/arun
}

\begin{abstract}
Thermal dehydration processes are highly energy-intensive and are found in almost all industrial sectors, accounting for 10 to 20 percent on national industrial energy consumption in developed countries. With escalating energy costs and need to mitigate environmental pollution due to emissions from combustion of fossil fuels, it is increasingly important to develop innovative drying technologies. Furthermore, drying also affects quality of the dried product due to physical and/or chemical transformations that may occur during the heat and mass transfer operation. With tens of thousands of products that are dried in hundreds of dryer types, it is a formidable task indeed to develop design and scale-up procedures of wide applicability. Attempts have been made over the past three decades to make fundamental and applied contributions to transport phenomena and material science aspects in drying of various forms of wet solids, pastes and liquids. This presentation will attempt to summarize the state-of-the-art as far as theoretical understanding of drying processes and provide examples of some new technologies being developed. Opportunities for challenging fundamental and modeling studies to enhance drying technologies will be identified. Illustrative results will be presented to show how mathematical modeling of spray, spouted bed and heat pump dryers can be utilized to develop new conceptual designs and to optimize operating conditions as a cost-effective route to intensify innovation in thermal dryer design.
\end{abstract}

\section{INTRODUCTION}

Almost all industrial sectors involve thermal dehydration during one or several phases of their manufacturing processes. Developed economies expend from $12-25 \%$ of their national industrial energy for drying operations depending on the product mixes they produce. This massive energy consumption mainly using fossil fuels directly impacts $\mathrm{CO}_{2}$ emission levels which are being curtailed actively under the Kyoto Protocol. To make matters worse, industrial dryers, most of which were designed during the era of cheap and abundant energy, typically operate at thermal efficiencies in the range 20 to 60 percent. Clearly there is tremendous scope for improvement of industrial drying technologies- a task that must logically begin with $R \& D$ to enhance our knowledge base on drying as well as dryers.

At the outset it is important to recognize that drying involves heat and mass transfer but it is only a part of the problem. It is important to be able to handle the wet material in the dryer and be able to produce a dried product of prescribed quality parameters- often not a simple task. In general what is optimal for heat and mass transfer is not optimal for drying. The latter is a coupled process involving transport phenomena and material science. It may involve physical transformations such as shrinkage, puffing, crystallization, cracking, glass transitions along with potential chemical or biochemical reactions. A mathematical model considering all these phenomena- many unpredictable a priori- is still a distant dream of drying researchers. A further complication arises from the fact that some 50,000 materials with very diverse physical/chemical properties need to be dried at different scales of production and with very different product quality. No wonder then that over 500 different types are reported in technical literature and some 100 types of dryers are available commercially. Contrast this with heat exchangers which can be designed reasonably reliably using standard software packages. No such luxury exists when it comes to heat and mass exchangers involving wet solids. Indeed, the large body of research literatures for dry solids becomes quite useless when one is faced with a corresponding wet solid! It is obvious that drying R\&D presents numerous challenging problems some of which are amenable to treatment with advanced computational and analytical tools, but the actual scope of the problem is truly of gigantic proportion.

The objective of this paper is to discuss some generic problems encountered in the design and optimization of industrial dryers, outline with some examples the nature of 
problems that can be treated via mathematical modelling and identify worthwhile R\&D needs and opportunities for those who wish to take up the challenge and make definitive and useful contribution to the advancement of the science, engineering and technology of thermal dehydration.

\section{NOMENCLATURE}

$\begin{array}{lll}A & {[\mathrm{MPa}]} & \text { Elastic bulk modulus of dried materials } \\ A & {\left[\mathrm{~m}^{2}\right]} & \text { The surface area of dried sample } \\ B=K R / A & {[-]} & \text { Coefficient of mass transfer (Biot Number) } \\ \mathrm{C}_{1}, \mathrm{C}_{2}, \ldots \mathrm{C}_{8} & {[-]} & \text { Constants } \\ D & {\left[\mathrm{~m}^{2} / \mathrm{s}\right]} & \text { Coefficient of diffusion } \\ f & {\left[\mathrm{~kg} / \mathrm{m}^{2} \mathrm{~s}\right]} & \text { Moisture flux } \\ h & {[\mathrm{~J} / \mathrm{kg}]} & \text { Enthalpy } \\ J_{0}, J_{1} & {[-]} & \text { Bessel functions of first kind of zero and first order } \\ k & {\left[\mathrm{~kg} / \mathrm{m}^{2} \cdot \mathrm{s}\right]} & \text { Coefficient of convective vapour exchange } \\ K & {[\mathrm{MPa}]} & \text { Elastic modulus due to shrinkage } \\ M & {[\mathrm{MPa}]} & \text { Elastic shear modulus of dried sample } \\ P & {[\mathrm{~Pa}]} & \text { Pressure } \\ r & {[\mathrm{~m}]} & \text { Radial direction } \\ R & {[\mathrm{~J} / \mathrm{mol} \cdot \mathrm{K}]} & \text { Universal gas constant } \\ T & {[\mathrm{~K}]} & \text { Temperature } \\ t & {[\mathrm{~s}]} & \text { Time } \\ X & {[\mathrm{~kg} / \mathrm{kg}]} & \text { Moisture content, dry basis } \\ Y & {[-]} & \text { Vapour content in drying air } \\ V & {\left[\mathrm{~m}^{3}\right]} & \text { Volume of dried sample } \\ V & {[\mathrm{~m} / \mathrm{s}]} & \text { Velocity }\end{array}$

Special characters

$\begin{array}{lll}\chi & {[-]} & \text { Depth scalar } \\ \varepsilon & {[-]} & \text { Volume fraction } \\ \varepsilon & {[-]} & \text { Volume strain } \\ \kappa^{(\mathrm{X})} & {[-]} & \text { Coefficient of humid expansion } \\ \lambda_{1}, \lambda_{\mathrm{n}} & {[-]} & \text { Enginvalue for Bessel functions } \\ \sigma & {[\mathrm{Pa}]} & \text { Stress } \\ \rho & {\left[\mathrm{kg} / \mathrm{m}^{3}\right]} & \text { Mass density } \\ \theta=\mathrm{X}-\mathrm{X}_{\mathrm{r}} & {[\mathrm{kg} / \mathrm{kg}]} & \text { Relative moisture content } \\ \mathrm{A} & {\left[\mathrm{kg} \cdot \mathrm{s} / \mathrm{m}^{3}\right]} & \text { Mass transport coefficient }\end{array}$

Subscripts

$\begin{array}{ll}a & \text { Air } \\ b & \text { Bulk } \\ e & \text { Equilibrium state } \\ e f f & \text { Effective } \\ g & \text { Gas phase } \\ l & \text { Liquid phase } \\ s & \text { Saturated state } \\ v & \text { Vapour } \\ \mathrm{w} & \text { Water } \\ 0 & \text { Initial state }\end{array}$

\section{INNOVATION IN DRYING}

Innovation is the engine that drives $\mathrm{R} \& \mathrm{D}$ and advances in technologies in general. As the world is getting "flatter", following Friedman's terminology, at an accelerating pace, global competition will provide the impetus for increased R\&D particularly in areas inevitably dependent on large consumption of energy. Already developing economies are making more than their share of drying R\&D over the past decades as reflected by publications on drying R\&D. Energy crisis of the early 70's drove drying R\&D, resulting in several conferences devoted to drying and even a new journal focused on drying. As energy costs dropped and levelled off drying R\&D continued but driven by need to reduce costs, improve quality and meet global competition. Recent hikes in energy costs will drive a second wave in drying $R \& D$ seeking to further improve the energy efficiency of entire drying/dehydration systems and potentially use renewable sources of energy where feasible. With rapidly increasing cost of physical experimentation and lack of talent, it is obvious that we need to turn to the almighty computer for cost-effective solutions and even as a way to intensity the innovation process. After all, we are facing the Digital Big Bang resulting in explosive growth of computerassisted engineering solutions.

There is one major problem that is limiting general utilization of mathematical models for innovation, design, operation and optimization of dryers. We do not yet have a reliable general theory of drying. In fact we do not have generalized mathematical models for even a particular type of dryer, for example for spray dryer for liquids or fluid bed dryer for particles. We must depend on empirical data and lab or even pilot scale tests to arrive at reliable full scale units; even then knowhow is of overriding value relative to current knowledge of these processes. Most models work well with specific product-dryer type combinations and that too with a significant amount of empiricism.

In this paper we will provide as examples modelling results for several dryer types examined at NUS viz. spray dryer for liquids, a spouted bed dryer of particles, pulse combustion dryer for liquids or as impingement dryer for sheets and heat pump dryer for heat-sensitive materials. The idea is to demonstrate how one can utilize models, even if not general and fully validated, can be used to innovate and examine new conceptual designs of dryers. They also show the formidable challenges ahead, leading to some ideas for future R\&D.

\section{MATHEMATICAL MODELS OF DRYING AND DRYERS}

We cannot provide a general overview of the wide assortment of modelling approaches, their relative merits and limitations, within the limited scope of this presentation. Table 1 is a summary of some of the model types (along with some references for the benefit of the interested reader). The type of model clearly depends on the object of modelling, type of product and drying equipment. Modelling of drying is a microscopic level approach that ideally is independent of the material. Even for the simplest well-defined porous material this poses severe problems. Compared to what we find in the literatures on porous media, the corresponding drying problem is complicated by the fact that the porous material can undergo physical deformation and even chemical reactions, change of moisture transport mechanisms during drying, can involve glass transitions, precipitation of solids, micro-crystallization etc. Some phenomena can occur at the micro-scale while others may occur at the macro-scale. The material being dried can be non-homogeneous and anisotropic. There can be porosity gradients within the product as it dries. Multiple modes of heat transfer can be applied simultaneously or intermittently to provide the heat of phase change. Indeed, the operating temperature and pressure range can range from below the triple point (freeze drying) to above the critical point (supercritical 
$\mathrm{CO}_{2}$ extraction of water form hydrogels). Drying times can range form milliseconds (inkjet droplets) to several months (in some drying kilns for wood). From this it is clear that it is unrealistic to expect to develop a generalized theory drying based only on fundamental properties of the material.

Table 1 Mathematical model for the drying process

\begin{tabular}{|c|c|c|}
\hline Model & Descriptions & Applications \\
\hline $\begin{array}{l}\text { Lattice } \\
\text { Boltzmann } \\
\text { Simulation }\end{array}$ & $\begin{array}{l}\text { Complex fluid phenomena at the } \\
\text { mesoscopic scale systems; } \\
\text { Simplicity, powerful method for } \\
\text { simulating flow in porous media; } \\
\text { Efficient to parallel computing }\end{array}$ & $\begin{array}{l}\text { Emulsification; } \\
\text { micro-filtration } \\
\text { process; few } \\
\text { application in drying }\end{array}$ \\
\hline $\begin{array}{l}\text { Population } \\
\text { balances }\end{array}$ & $\begin{array}{l}\text { Modelling discrete or particulate } \\
\text { materials using a population density } \\
\text { function; } \\
\text { Accuracy and convenience in } \\
\text { description of particle properties } \\
\text { Expensive in computation }\end{array}$ & $\begin{array}{l}\text { Particulates in } \\
\text { fluidized beds [1]. } \\
\text { Particle formation, } \\
\text { breakage, etc }\end{array}$ \\
\hline $\begin{array}{l}\text { Discrete } \\
\text { element } \\
\text { model }\end{array}$ & $\begin{array}{l}\text { Tracking the motion of individual } \\
\text { particles. } \\
\text { Accuracy in description of } \\
\text { dynamics of particulate phase. } \\
\text { Expensive in computation cost }\end{array}$ & $\begin{array}{l}\text { Particle mixing in a } \\
\text { drum[2], particle } \\
\text { dynamics in fluid, } \\
\text { spray bed, etc. }\end{array}$ \\
\hline $\begin{array}{l}\text { Pore } \\
\text { network } \\
\text { model }\end{array}$ & $\begin{array}{l}\text { Simulating flow in porous bodies. } \\
\text { Influence of Pore- structures on } \\
\text { drying kinetics. } \\
\text { Microscopic description of transport } \\
\text { phenomena } \\
\text { Increased model performance. }\end{array}$ & $\begin{array}{l}\text { Drying of Porous } \\
\text { materials [3] }\end{array}$ \\
\hline $\begin{array}{l}\text { Fractal } \\
\text { analysis }\end{array}$ & $\begin{array}{l}\text { Powerful tool for characterizing } \\
\text { materials and processes. } \\
\text { Self-similarity theory. } \\
\text { Complex and chaotic problem. } \\
\text { Efficiency in predicting particle } \\
\text { properties } \\
\text { Difficulty in estimation of fractal } \\
\text { dimension }\end{array}$ & $\begin{array}{l}\text { Particle diameter } \\
\text { distribution, material } \\
\text { properties[4] }\end{array}$ \\
\hline $\begin{array}{l}\text { Computati } \\
\text { onal fluid } \\
\text { dynamics } \\
\text { (CFD) } \\
\text { model }\end{array}$ & $\begin{array}{l}\text { Comprehensive model for } \\
\text { engineering problem. } \\
\text { Governing equations + boundary } \\
\text { and initial equations. } \\
\text { Higher sophistication when coupled } \\
\text { with other models } \\
\text { Available in commercial software } \\
\text { packages. } \\
\text { Active in system design and process } \\
\text { optimization }\end{array}$ & $\begin{array}{l}\text { Spray, fluid, spouted } \\
\text { bed drying[5-6], } \\
\text { wider applications }\end{array}$ \\
\hline $\begin{array}{l}\text { Finite } \\
\text { element } \\
\text { analysis }\end{array}$ & $\begin{array}{l}\text { Modelling moisture transfer in wet } \\
\text { solid. } \\
\text { No need for additional equation to } \\
\text { assure continuity cross common } \\
\text { boundaries. } \\
\text { Easily handle complex geometries } \\
\text { and mesh gradation. } \\
\text { Easily handle mixed boundary } \\
\text { conditions } \\
\text { Easily programmed. }\end{array}$ & $\begin{array}{l}\text { Grains, soybean, rice } \\
\text { drying, thin-layer } \\
\text { drying, etc [7] }\end{array}$ \\
\hline
\end{tabular}

Table 2 Mathematical models for dryers

\begin{tabular}{|l|l|l|}
\hline Model Type & Description & Applications \\
\hline $\begin{array}{l}\text { Response } \\
\text { surface } \\
\text { methodology }\end{array}$ & $\begin{array}{l}\text { A statistical technique that uses } \\
\text { regression analysis to develop a } \\
\text { relationship between input and } \\
\text { output parameters }\end{array}$ & $\begin{array}{l}\text { Process } \\
\text { optimization[8], } \\
\text { finding significant } \\
\text { factors }\end{array}$ \\
\hline $\begin{array}{l}\text { Multivariate } \\
\text { analysis }\end{array}$ & $\begin{array}{l}\text { A collection of statistical } \\
\text { procedures that involve } \\
\text { observation and analysis of } \\
\text { multiple measurements }\end{array}$ & $\begin{array}{l}\text { Optimization, } \\
\text { finding significant } \\
\text { factors }\end{array}$ \\
\hline Data mining & $\begin{array}{l}\text { Automatic searching of large } \\
\text { volumes of data to establish } \\
\text { relationships and identify } \\
\text { patterns }\end{array}$ & $\begin{array}{l}\text { Statistical } \\
\text { techniques, } \\
\text { machine learning }\end{array}$ \\
\hline $\begin{array}{l}\text { Neural } \\
\text { networks }\end{array}$ & $\begin{array}{l}\text { An artificial neural network } \\
\text { model is an interconnected } \\
\text { group of functions that can } \\
\text { represent complex input-output } \\
\text { relationships }\end{array}$ & $\begin{array}{l}\text { Process control [9- } \\
\text { 10], product } \\
\text { quality, wider } \\
\text { applications }\end{array}$ \\
\hline $\begin{array}{l}\text { Genetic } \\
\text { algorithms }\end{array}$ & $\begin{array}{l}\text { Search algorithms in a } \\
\text { combinational optimization } \\
\text { problem }\end{array}$ & $\begin{array}{l}\text { Parameters } \\
\text { optimization [11], } \\
\text { process control } \\
\text { method [12] }\end{array}$ \\
\hline Fuzzy logic & $\begin{array}{l}\text { Fuzzy set theory that permits } \\
\text { the gradual assessment of the } \\
\text { membership of elements }\end{array}$ & $\begin{array}{l}\text { Dryer selection } \\
\text { [13], control [14] }\end{array}$ \\
\hline
\end{tabular}

Indeed, mathematical models also help with scale-up and optimization of operating conditions. Furthermore, modelbased control is becoming increasingly popular to ensure good thermal efficiency, safe operation and product quality. Thus, out thesis is that mathematical models of dryers are a valuable prelude to arriving at innovative designs of dryers. Following are a couple of recent examples from our laboratory.

It should be noted at the outset that modelling of dryers basically requires two sub-models, viz. a drying model and an equipment model. The former deals with the drying characteristics of the material being dried and the latter deals with the manner in which the material is handled in the equipment which affects the heat and mass transfer rates and residence times the material sees within the dryer. Both types of models today need considerable amount of empirical data e.g. drying kinetics over parameter ranges to be encountered in the dryer, behaviour of the material in the equipment under a range of parameters the dryer may be operated under etc. The need to model solids and solids flow, that too when the solids are wet and hence maybe sticky with tendency to form lumps or agglomerates, presents unusually complex problem to modellers. We will consider just a few examples in this presentation.

Huang (2005) developed a CFD model to predict flow patterns and overall drying performance of different spray dryer designs [5]: the conventional cylinder-on-cone one; the dryer with two pressure nozzles, rotating disk atomizer and ultrasonic nozzle; the dryer with conical, hour-glass shape and lantern shape chambers. Furthermore, the CFD model was used to 
evaluate an innovative one-stage and two-stage, two dimensional horizontal spray dryer (HSD) concept. Figure 1 shows predicted particle trajectories inside various chamber geometries design in one stage HSD dryer, where Figure1 (A) show a basic rectangular box design similar to a commercial horizontal spray dryer (Ceroges, 2004). From Figure 1, it can be seen that the chamber volume is not fully used in Case A and $\mathrm{B}$. The particle deposit on bottom wall is reduced and the chamber volume is fully utilized in Case C. However, a recirculation zone near the outlet will lead to backflow of ambient air. Condensation may occur and it may cause large deposit and poor product quality. Case $\mathrm{D}$ and $\mathrm{E}$ can be considered as good conceptual designs: high chamber volume utilization ratio, reduced wall deposits, sufficient particle residence time, etc. If the evaporation rate per unit volume is considered, Case D gives better performance, about 25\%, more than case $\mathrm{E}$. Thus, Case $\mathrm{D}$ is the best one among proposed geometry designs
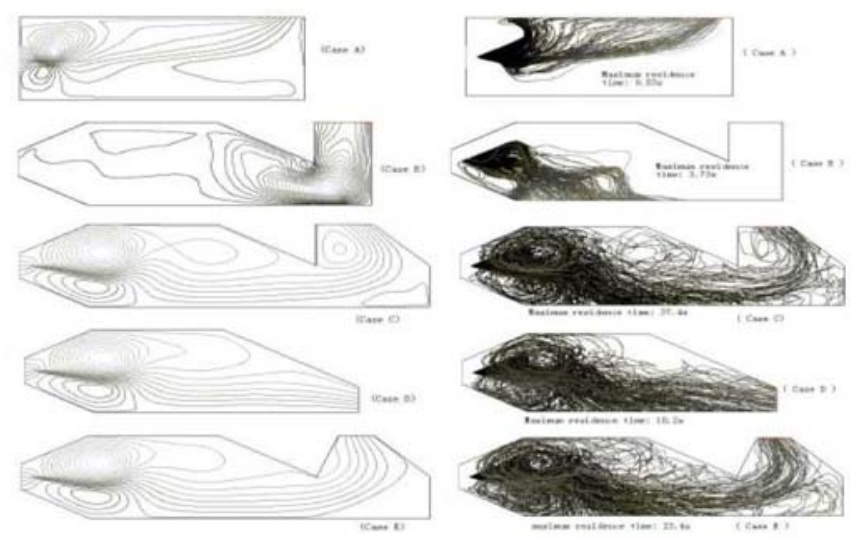

Figure 1 Predicted flow stream and particle trajectories for various one stage HSD designs

A CFD two-fluid model was developed by Wu to describe the gas-particle flow behaviours of a cylindrical spouted bed under a steady spouting jet [6]. The typical flow pattern of the spouted bed is shown in Figure2 (a), where a stable spout, fountain and annulus regions were observed clearly. Calculated particle velocities and concentrations agree well with the published experimental data. The CFD model was also used to evaluate the influence of operation parameters such as particle size, density, and pulsating jet, etc on flow pattern of the bed. Figure2 (b) show a bubble generate inside the bed under a pulsating jet and is moving to the freeboard. The bubble size and shape is related to the frequency of the pulsating jet and bubbles will disappear when frequency exceeds a critical value. Bubble formation and resulting flow instabilities were also described. The drying kinetics of grains in the spouted bed dryer was also investigated computationally. Figure 3(b) shows the predicted mass fraction of vapour inside the bed after a drying time of 1.2 second. Similar distributions can also obtained for gas temperature, particle temperature, moisture, density, water evaporation rate, etc at different drying times. Such predictions can provide important information on the flow field within the spouted beds for process design and scale-up.

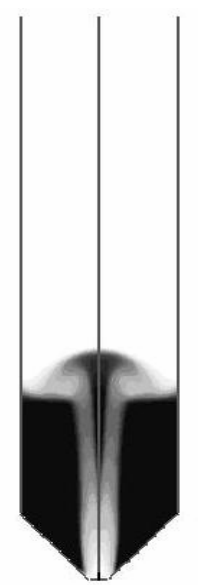

(a) Steady spouting

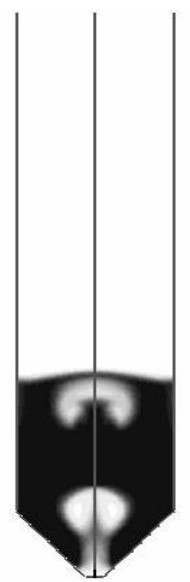

(b) Bubbles generaton
in umsteady spouting

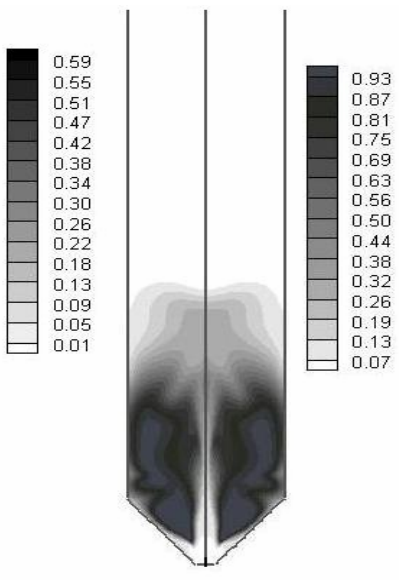

(c) Mass fraction of vapor
Figure 2 Particle concentration distribution insider the bed under steady (a) and unsteady spouting jet (b) and mass fraction distribution of vapor at drying time of $1.2 \mathrm{~s}$ $\left(\mathrm{H}=0.325 \mathrm{~m}, \rho_{\mathrm{s}}=2500 \mathrm{~kg} / \mathrm{m}^{3}, \mathrm{~d}_{\mathrm{s}}=1.41 \mathrm{~mm}, \mathrm{U}_{\mathrm{ms}}=0.54 \mathrm{~m} / \mathrm{s}\right)$

\section{Thermo-Mechanical Models of Drying}

When water is removed during drying processes, pressure imbalance is produced between inner pressure of the material and the external pressure, generating contracting stresses that can lead to material shrinkage or collapse, changes in shape. When rapid drying rate conditions are used and intense moisture gradient through the materials are observed, shrinkage is not uniform resulting in the formation of unbalanced stress. In this condition, surface cracking may occur leading to permanent deformation or even failure of the material. To avoid such undesired effects, simulation tools that can handle simultaneously the drying problem and the coupled mechanical problem are necessary.

The thermo-mechanical models often comprise of simplified drying models based on the diffusion equation with different coefficients and boundary conditions for the first and second periods of drying. The drying models enable estimation of moisture content distribution in the dried sample. The magnitude of stresses/shrinkage depends inter alia on the moisture distribution gradient. Different models for dryinginduced stresses and shrinkages have been developed to estimate these mechanical effects.

\section{Distribution of moisture content}

The distributions of moisture content are often evaluated based on the diffusion model equations. Taking a pine-wood disk as an example [15], the moisture transfer during the first period of drying, also called the constant drying rate period, is described by the following differential equation 


$$
\frac{\partial \vartheta^{(I)}}{\partial t}=D^{(I)}\left(\frac{\partial^{2} \vartheta^{(I)}}{\partial r^{2}}+\frac{1}{r} \frac{\partial \vartheta^{(I)}}{\partial r}\right)
$$

(1)

The boundary and initial condition is given by:

$\left.\frac{\partial \vartheta^{(I)}}{\partial t}\right|_{r=0}=0$

$-\left.A^{(I)} \frac{\partial \vartheta^{(I)}}{\partial t}\right|_{r=R}=k^{(I)}\left(Y_{n}-Y_{a}\right)=$ const

$\left.\vartheta^{(I)}\right|_{t=0}=\theta_{0}=$ const

(4)

where $Y_{n}$ and $Y_{a}$ are the vapour contents in the drying air close to and far form the disk surface, and $k^{(I)}$ is the coefficient of convective vapour exchange between the dried disk and the ambient air, respectively.

The solution of the above initial-boundary value problem was constructed by Kowalski (2005) with the help the separation of variables method and its final form is described as

$$
\vartheta^{(I)}{ }_{(r, t)}=\theta_{0}-2 R B^{(I)} C\left\{\frac{t}{t^{(I)}}+\sum_{n=0}^{\infty}\left[1-\frac{J_{0}\left(\lambda_{n} r / R\right)}{\lambda_{n}^{2} J_{0}\left(\lambda_{n}\right)}\right]^{e-\lambda_{n}^{2} \frac{t}{t^{(I)}}}\right\}
$$

where $B^{(I)}=k^{(I)} R / A^{(I)}, C=\left(Y_{n}-Y_{a}\right) / R, t^{(I)}=R^{2} / D^{(I)}$

and $\lambda \mathrm{n}$ is the $\mathrm{n}$-th eigenvalue calculated from the characteristic equation

$J_{1}\left(\lambda_{n}\right)=0 \rightarrow\left\{\lambda_{n}\right\}=\left\{\lambda_{1}, \lambda_{2} \ldots ..\right\}$

(6)

Here $J_{0}$ and $J_{1}$ are Bessel functions of the first kind of zero and first order, respectively.

Similarly, the moisture distribution in the disk during the second period of drying reads

$$
\begin{aligned}
\theta^{(\Pi)}(r, t)=\theta_{e}+2 \sum_{n=0}^{\infty} & \left\{\left(b-\vartheta_{e}\right) B^{(\Pi)}-a\left[\left(1-\frac{4}{a_{n}^{2}}\right) B^{(\Pi)}+2\right]\right\} \\
& \times \frac{J_{0}\left(a_{n} r / R\right)}{a_{n}^{2}+B^{(\Pi)^{2}} J_{0}\left(a_{n}\right)} \exp \left(-a_{n}^{2} \frac{t-t_{s}}{t^{(\Pi)}}\right)
\end{aligned}
$$

(7)

Here $a_{n}$ is the nth enginvalue calculated from the characteristic equation of the form

$$
J_{1}\left(a_{n}\right)=\frac{B^{(\Pi)}}{a_{n}} J_{0}\left(a_{n}\right) \rightarrow\left\{a_{n}\right\}=\left\{a_{1}, a_{2} \ldots . .\right\}
$$

Hence, equations (5) and (7) enable estimation of moisture content distribution in the dried sample in several instants of time. When temporal moisture content distribution is obtained, the shrinkage of materials and stresses can be then determined.

\section{Shrinkage}

The moisture content of materials decreases during drying, resulting in a decrease of its volume-shrinkage. Generally, mathematical models for shrinkage can be classified as empirical and fundamental ones. Empirical models are relatively simple methods which develop an empirical correlation between shrinkage and moisture content, including occasionally the relevant process parameters like temperature and humidity of air. The correlation can be linear: Lozano et al (1980) used the equation $D_{R}=c_{1}+c_{2} X$ to model shrinkage of the cylindered apple [16]. The reduced dimension $D_{R}$ refers to volume; it can also be non-linear: Vazquez, et al (1999) applied the equation $D_{R}=c_{3}+c_{4} X+c_{5} X^{3 / 2}+c_{6} \exp \left(c_{7} X\right) \quad$ to simulate shrinkage of the slab garlic [17]. The reduced dimension is thickness. These empirical models usually give good fit to experimental data, but their use is limited because of their dependence on the drying conditions and on the material characteristics. They require extensive experimental testing and should not be extrapolated.

Fundamental models, based on mass balances, density and porosity definitions, assume in most cases additivity of the volumes of the different phases of the system. That is, shrinkage compensates for moisture loss. Suzuki, et al (1976) used a linear equation to model the shrinkage of cube carrot, potato, sweet potato, and radish: $\frac{V}{V_{0}}=c_{7} X+1$ where $c_{7}=\frac{1-c_{8}}{X_{0}-X_{e}}$ and $c_{8}=\frac{\left(X_{e}+1\right) \rho_{0}}{\left(X_{0}+1\right) \rho_{e}}$ [18]. The reduced dimension is area: $\frac{A}{A_{0}}=\left(\frac{V}{V_{0}}\right)^{2 / 3}$. Other types of fundamental models for shrinkages were summarized in Reference [19]. Compared with empirical models, it is not usually necessary for fundamental models to obtain experimental shrinkage values at every process condition. It also allows the prediction of moisture content and/ or change in volume to be obtained without complicated mathematical calculations. However, the quality of the fundamental models fitted to experimental data is relatively low.

\section{Drying- induced stresses}

Kowalski $(2004,2007)$ discussed the drying induced stress during the wood drying process [15, 20]. The author assumed that wood beyond the fibre saturation point (FSP) does not shrink and has the lowest mechanical strength despite its moisture content. Unsaturated wood, on the other hand, shrinks when the moisture content decreases. The shrinkage is then regarded as proportional primarily to the change of moisture content; the volumetric strain due to shrinkage is $\varepsilon=3 k^{(X)} \theta$. The coefficient of humid expansion fulfils the following criterion

$$
k^{(X)}=\left\{\begin{array}{cc}
0 & \theta_{s} \leq \theta \leq \theta_{0} \\
k_{0}^{(X)} & \theta_{e} \leq \theta \leq \theta_{s}
\end{array}\right.
$$


The wood disk is assumed to be elastic and then, the physical relations in the saturated region (over FSP) of the cylindrical wood disk is presented [15]

$$
\left\{\begin{array}{c}
\sigma_{r r}=2 M^{(S)} \varepsilon_{r r}+A^{(S)} \varepsilon \\
\sigma_{\varphi \varphi}=2 M^{(S)} \varepsilon_{\varphi \varphi}+A^{(S)} \varepsilon \\
\sigma_{z z}=0+A^{(S)} \varepsilon
\end{array}\right.
$$

(9)

Physical relation (9) does not contain a shrinkage term. The elastic shear modulus, $\mathrm{M}^{(\mathrm{S})}$, and the elastic bulk modulus, $\mathrm{A}^{(\mathrm{S})}$, are independent of moisture content. Similarly, the physical relations for elastic unsaturated wood read

$$
\left\{\begin{array}{c}
\sigma_{r r}=2 M^{(U S)} \varepsilon_{r r}+A^{(U S)} \varepsilon-3 K^{(U S)} k^{(X)} \theta^{(\Pi)} \\
\sigma_{\varphi \varphi}=2 M^{(U S)} \varepsilon_{\varphi \varphi}+A^{(U S)} \varepsilon-3 K^{(U S)} k^{(X)} \theta^{(\Pi)} \\
\sigma_{z z}=0+A^{(S)} \varepsilon-3 K^{(U S)} k^{(X)} \theta^{(\Pi)}
\end{array}\right.
$$

(10)

Physical relations (10) in the unsaturated region contain the shrinkage term and the elastic shear, bulk modulus are a function of moisture content. Substituting equation (5) and (7) into the physical relation (9-10), we can obtain the differential equation for determining stresses. Given the initial and suitable boundary conditions, we can then obtain the solutions for the differential equations and finally, determine the stresses distribution.

The simulation results of above-noted stress model showed that the drying stresses result mainly from a gradient of moisture content in the pores of dried body. The stresses increase with drying rate and the size of the body and inversely related to the permeability of the structure. Fracture in many cases seems to result from flaws generated by the irregularity of the drying front as it enters the body at critical point.

In summary, the thermo-mechanical model can be used to estimate shrinkage, capillary forces and thermal tensions cause stresses in drying bodies. It is simple and can be improved. The thermo-mechanical models have been obtained wider applications in drying and are slightly modified on a case- to case basis. Table 2 lists the applications of thermo-mechanical models reported in the literature for various materials and its geometries, including organic, inorganic, biological materials. This is only an illustrative list.

Table 3 Applications of thermo-mechanical models to drying [21]

\begin{tabular}{|l|l|}
\hline Materials modelled & Shape \\
\hline $\begin{array}{l}\text { Agar gel, Glucose-calcium alginate gel, } \\
\text { polyacrylamid gel, Alumina gel, Clay, } \\
\text { Cassava root, Grape, Plum, soybean }\end{array}$ & \\
\hline $\begin{array}{l}\text { Gelatin, Paper, Regenerated cellulose, } \\
\text { Starch from modified corn, rice, Clay, }\end{array}$ & \\
Concrete, Epoxy-amine painting, Sol-gel, & \\
Apple, Banana, Carrot, Grape bed, Ham, & \\
Mango, Potato, Sugar beet root & \\
\hline
\end{tabular}

\begin{tabular}{|l|l|}
\hline $\begin{array}{l}\text { Regenerated cellulose, Ceramic material, } \\
\text { Clay, Potato, Wood }\end{array}$ & Finite 2D slab \\
\hline $\begin{array}{l}\text { Agar gel, High amylase starch powder, } \\
\text { Clay, Carrot with Teflon filling, Cassava } \\
\text { root, Green bean, Potato, etc }\end{array}$ & $\begin{array}{l}\text { Finite 2D } \\
\text { cylinder }\end{array}$ \\
\hline $\begin{array}{l}\text { Spaghetti, Starch-gluten gel, Clay, Banana, } \\
\text { Paddy rice, Wood }\end{array}$ & $\begin{array}{l}\text { Infinite } \\
\text { cylinder }\end{array}$ \\
\hline Clay, Apricot, Corn kernels & $\begin{array}{l}\text { Irregular 2D } \\
\text { shape }\end{array}$ \\
\hline Starch, sucrose-starch system, Clay, Carrot & Finite 3D slab \\
\hline
\end{tabular}

\section{Multiscale Models for Drying}

Perre (2002) has discussed the characteristics and needs for multi-scale models in drying of such materials as wood and paper [22]. When the overall drying behaviour is influenced by both what happens at the micro scale and what happens at the macro scale, we need multi-scale models for proper representation of the drying behaviour. For example in the convective drying of an oak with radio-frequency heating, the power field is computed by solving Maxwell's equations (micro scale). This field depends on the dielectric properties of wood, hence on the temperature and moisture content fields (macro scale). Similarly, the temperature and moisture content fields depend on the power fields. Under such conditions, a multiscale model is needed. In multiscale models, the time scales of moisture movement as well as the mechanism of moisture transport can be different at the two scales. In drying this is often related to the physical structure of the material modelled as well.

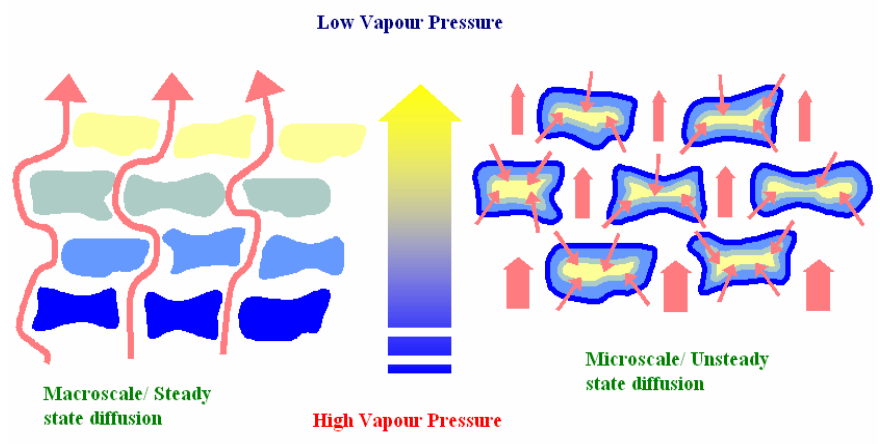

Figure 3 Schematics of two scales in wood drying

Taking vapour diffusion inside wood as an example [23], we show how a multiscale model can be developed and the relationship between micro and macro scale. Figure 3 shows schematically the anatomical structure of wood and the vapour diffusion mechanisms. Two scales exist for vapour diffusion inside the wood. Transport mechanisms take place at the microscopic scale, i.e. bound-water diffusion through cell walls and vapour diffusion following Fick's law. At the microscopic scale, these two fluxes can be expressed as follows

$f_{b}=-\rho_{s} D_{b} \nabla X_{b}$

(Bound-water

flux)

$$
f_{v}=-\rho_{g} D_{v} \nabla \omega_{v} \quad \text { (Vapour }
$$


On assuming isothermal conditions and constant total pressure, the microscopic vapour flux can be expressed with the gradient of the boundary-water content as the driving force by equation 12.

$$
f_{v}=-\left(\frac{M_{v}}{R T} D_{v} \frac{\partial P_{v}}{\partial X_{b}}\right) \nabla X_{b}
$$

Transport mechanisms also occur at the macro scale, i.e. vapour diffusion through lumen, pores and pits. Vapour diffusion at macro scale will change the state variable (density, moisture content, temperature, etc) of the wood. Perre (2007) proposed a set of macroscopic equations for simulation of the drying process [23].

Water conservation

$\frac{\partial}{\partial t}\left(\varepsilon_{w} \rho_{w}+\varepsilon_{g} \rho_{v}+\bar{\rho}_{b}\right)+\nabla\left(\varepsilon_{w} \bar{v}_{w}+\varepsilon_{g} \bar{v}_{g}+\overline{\rho_{b} v_{b}}\right)$

$$
=\nabla\left(\rho_{g} \bar{D}_{e f f} \nabla \omega_{v}\right)
$$

(14)

Energy conservation

$$
\begin{aligned}
& \frac{\partial}{\partial t}\left(\varepsilon_{w} \rho_{w} h_{w}+\varepsilon_{g}\left(\rho_{v} h_{v}+\rho_{a} h_{a}\right)+\bar{\rho}_{b} \bar{h}_{b}+\rho_{o} h_{s}-\varepsilon_{g} P_{g}\right) \\
& +\nabla\left(\varepsilon_{w} h_{w} \bar{v}_{w}+\left(\rho_{v} h_{v}+\rho_{a} h_{a}\right) \bar{v}_{g}+h_{b} \overline{\rho_{b} v_{b}}\right)= \\
& \nabla\left(\rho_{g} \bar{D}_{e f f}\left(h_{v} \nabla \omega_{v}+h_{a} \nabla \omega_{a}\right)+\overline{\bar{\lambda}}_{\text {eff }} \nabla T\right)+\Phi \\
& )
\end{aligned}
$$

Air conservation

$$
\frac{\partial}{\partial t}\left(\varepsilon_{a} \rho_{a}\right)+\nabla\left(\rho_{a} \bar{v}_{g}\right)=\nabla\left(\rho_{g} \bar{D}_{e f f} \nabla \omega_{a}\right)
$$

(16)

Here the gas-and liquid-phase velocities are given by the generalized Darcy's Law:

$$
\bar{v}_{l}=\frac{\overline{\bar{K}}_{l} \overline{\bar{k}}_{r l}}{\mu_{l}} \nabla \varphi_{l} \text { and } \nabla \varphi_{l}=\nabla P_{l}-\rho_{l} g \nabla \chi
$$

where $l$ is $w, g$, the quantity $\varphi$ is known as the phase potential, and $\chi$ is the depth scalar.

The averaged value of the variable $\varphi$, indicated by a bar, is defined as

$$
\bar{\varphi}=\frac{1}{V_{R E V}} \int_{R E V} \varphi d V
$$

The $R E V$ (representative elementary volume) is larger enough for average local quantities to be defined but small enough to avoid variations due to macroscopic gradients. In macroscopic equations, subscript eff denotes the "effective" property that has to be determined experimentally or by using a predictive scaling approach.

The scaling approach is a mathematical tool, which allows the macroscopic properties to be predicted from a microscopic description of a heterogeneous medium. If the scales are assumed to be independent, which allows the solution to be computed only once at the smaller scale and subsequently used in the macroscopic set of equations. A technique called "homogenization" can reduce the multi-scale approach to a change of scale, resulting in less demanding in computational resources and in applied mathematics. If the scale levels can not be considered as independent, other strategies have been proposed through which several scales can be considered simultaneously, such as the parallel flow model, mesocopic model [24], distributed microstructure models [25], etc. For example, the mesocopic model deals with the microscopic detail at the macroscopic level. This is a continuous model for which physical parameters change rapidly in space. Such models are able to capture the mechanisms and interactions between different scales, but they need massive computer resources. Furthermore, they work only when the ratio between the micro scale and macro scale is close to unity. An example of the mesoscopic approach is the drying of softwood containing annual growth rings [24].

Perre and Remond (2006) used a multiscale (dual-scale) model to simulate the drying behaviour of a whole stack in an industrial kiln [26]. In their dual-scale model, each micromodel simulates the coupled heat and mass transfer within one single board. The macro model deals with heat and mass transfer in each airflow channel between two adjacent board layers. Simulation results showed that this model can predict the different drying kinetics of each board in the case of identical boards located at different positions in the stack. The interaction between each board and the fact that the air flow changes the drying condition from the inlet to outlet explains the differences in drying kinetics. Thus, this approach allows one to formulate the kiln specifications and stack configuration to be optimized (sticker thickness, air velocity, stack width, etc). Furthermore, by its ability to simulate the drying of boards with different properties, the natural variability of wood can be accounted for to improve the drying schedule. Hence, the multiscale model shows high application potential in drying, especially of porous materials such as wood, ceramics, etc.

\section{R\&D NEEDS IN DRYING}

As is evident from the previous discussion, thermal drying of solids is a complex phenomenon that has defied development of a universal theory. Unlike heat exchangers, design and analysis of the heat and mass exchangers (viz. dryers) is not amenable to use of appropriate software. Indeed, one needs software for each product/equipment combination with a few notable exceptions. A relatively simple problem of heat and mass transfer in a deformable variable porosity porous medium is a formidable problem if the porosity itself must be part of the computation. The thermophysical property data needed are simply too complex to measure and generalize. In fact, one must carry out experiments which are more complex than those required to measure drying kinetics which such data are supposed to predict via an appropriate mathematical model. Added to this one has the complexity of physical transformations such as shrinkage, puffing, precipitation, crystallization, glass transition solute transport etc and chemical 
reactions as well. Heat may be supplied by any one of the several modes of heat transport in a continuous or time-varying manner. Drying is not a simple heat and mass transfer operation; one must also look carefully at the quality parameters which depend on the product being dried. It is hardly surprising, therefore, that no unified drying theory can be expected in the foreseeable future.

Mujumdar (2004, 2007) has discussed and presented a large number of ideas for drying R\&D and innovation in drying [2728]. These are not repeated here; the interested reader is directed to these references for details. Kudra and Mujumdar (2001) have discussed a multitude of industrial drying technologies which deserve R\&D for optimization [29]. Industry in general is conservative and understandably riskaverse. Nonlinearity of the drying operation means scale-up from small to large scale is generally very difficult and often relies on empiricism and knowhow. Development of reliable models of drying and dryers will help to make the design more reliable. Model-based control of dryers can enhance the costeffectiveness of dryers. Models can also be used to cut down the rising cost of experimentation and thus enhance innovation.

With the advent of the bio-nano and pharmaceutical technologies, drying faces new challenges not tackled earlier. This provides new opportunities for challenging R\&D. Even in conventional areas like drying of paper, ceramics, wood etc there is scope to make the processes more energy-efficient, environmentally friendly and safe. Reliance on fossil fuels needs to be reduced as well by use of renewable energy sources.

In the coming decade one should see more industrial technologies utilizing superheated steam as the drying medium because of its numerous inherent advantages. Solar dryers utilizing photovoltaics and possibly wind energy to boost the drying rates and efficiency will become more popular even in developed countries. Use of bio-gas, bio-diesel instead of oil or natural gas will become more common as petroleum products escalate in price. On the other hand use of agricultural land to grow "fuels" may cause undue pressure on the food supply around the world. More efficient combustion technologies which also provide thrust for gas movement in dryer, e.g. pulse combustion, will become more common. Use of low rank coal which contains large volume of water (similar to peat) will increase along with the need to dewater and dry coal costeffectively possibly using superheated steam. Changes in technologies in one field will have an impact on technology in a related field.

\section{CONCLUDING REMARKS}

This paper has focused on a small area of R\&D needs in the vast field of thermal drying. As an energy consuming operation responsible for $10-25 \%$ of national industrial use in the developed countries, and an increasing fraction in the emerging economies as well, there is strong incentive to understand this operation better. Aside from attempts to develop workable models for drying and dryers, it is also essential to carry out careful experiments on different size equipment to test models for scale-up. Aside from models for heat and mass transfer it is also necessary to develop predictive models for the quality parameters of the dried products. Finally, the need for industry-academia interaction in successful development of innovative dryers cannot be overemphasized due to the applied nature of this entire field. With potential legislations limiting carbon emissions and imposition of carbon tax, it will be essential in the next few decades to come up with ultraefficient, compact drying systems to remain globally competitive. As noted in this work, intelligent utilization of reliable mathematical models can intensity and accelerate the innovation process and search for truly disruptive drying technologies to supplant today's inefficient drying technologies.

\section{REFERENCES}

[1] Seydel, P., Blomer, J., Bertling, J., Modelling particle formation at spray drying using population balances, Drying Technology, Vol.24, 2006, pp137-246

[2] Li, J., Campbell, G.M., Mujumdar, A.S., Discrete modelling and suggested measurement of heat transfer in gas-solids flows, Drying Technology, Vol.21, 2003, pp979-994

[3] Kowalski, S.J. (ed.), Drying of porous materials, Springer, 2007, p.236

[4] Zhu, W.X., Dong, T.Y., Cao, C.W., Li, D., Fractal modelling and simulation of the developing process of stress cracks in corn kernel, Drying Technology, Vol.22, 2004, pp59-69

[5] Huang, L.X., Mujumdar, A.S. Development of a new innovative conceptual design for horizontal spray dryer via mathematical modelling, Drying Technology, Vol.23, 2005, pp 1169-1187

[6] Wu, Z.H., Mujumdar, A.S., Simulation of the hydrodynamics and drying in a spouted bed dryer, Drying Technology, Vol. 25, 2007, pp1-16

[7] Turner, I., Mujumdar, A.S. (ed.), Mathematical modelling and numerical techniques in drying technology, Marcel Dekker Inc, 1997, p.679

[8] Zhang, M., Li, C.L., Ding, X.L., Cao, C.W., Optimization for preservation of Selenium in sweet pepper under low-vacuum dehydration, Drying Technology, Vol.21, 2003, pp569-579

[9] Palancar, M.C., Aragon, M.J., Castellanos, Neural network model for fluidized bed dryer, Drying Technology, Vol.19, 2001, pp1023-1044

[10] Islam, M.R., Sablani, S.S., Mujumdar, A.S., An artificial neural network model for prediction of drying rates, Drying Technology, Vol.21, 2003, pp1867-1884

[11] Li, X.M., Lin, S.X.Q., Chen, X.D., Chen, L.Z., Pearce, D., Inactivation kinetics of probiotic bacteria during the drying of single milk droplets, Drying Technology, Vol.24, 2006, pp695701

[12] Sanjabi, F., Upreti, S.R., Dhib, R, Optimal control of continuous infrared dryers, Drying Technology, Vol.24, 2006, 581-587

[13] Baker, C.G.J., Lababidi, H.M.S., Masters, K., A fuzzy expert system for the selection of spray drying equipment, Drying Technology, Vol.22, 2004, pp237-258

[14] Liu, H.L., Zhang, J.L., Tang, X.J., Lu, Y.J., Fuzzy control of mixed-flow grain dryer, Drying Technology, Vol.21, 2003, pp807-819

[15] Kowalski, S.J., Wojciechowska, A.S., Stresses in dried wood. modeling and experimental identification, Transport in Porous Media, Vol.66, 2007, pp145-148

[16] Lozano, J.E., Rotstein, E., Urbicain, M.J., Total porosity and open-pore porosity in the drying of fruits, Journal of Food Science, Vol.45, 1980, pp1403-1407 
[17] Vazquez, G., Chenlo, F., Moreira, R., Costoyas, A., The dehydration of garlic. I. Desorption isotherms and modeling of drying kinetics, Drying Technology, Vol.17, 1999, pp1095-1108

[18] Suzuki, K., Kubota, K., Hasegawa, T., Hosaka, H., Shrinkage in dehydration of root vegetables, Journal of Food Science, Vol.41, pp1189-1193

[19] Mayor, L., Sereno, A.M., Modeling shrinkage during convective drying of food materials: a review, Journal of Food Engineering, Vol.61, 2004, 373-386

[20] Kowalski, S.J., Molinski, W., Musielak, G., Identification of fracture in dried wood based on theoretical modelling and acoustic emission, Wood Science and Technology, Vol.38, 2004, pp35-52

[21] Katekawa, M.E., Silva, M.A., A review of drying models including shrinkage effects, Drying Technology, Vol. 24, 2006, pp5-20

[22] Perre, P., Wood as a multi-scale porous medium: observation, experiment, and modeling, Proceeding of the First International Conference of the European Society for Wood Mechanics, Lausanne, Switzerland, 2002, pp365-384

[23] Perre, P., Mulitscale aspects of heat and mass transfer during drying, Transport in Porous Media, Vol.67, 2007, pp59-76

[24] Perre, P., Turner, I.W., A heterogeneous wood drying computational model that accounts for materials property variation across growth rings, Journal of Chemical Engineering, Vol.86, 2002, pp117-131

[25] Hornug, U., Homogenization and porous media, SpringerVerlag, New York, 1997

[26] Perre, P., Remond, R., A dual-scale computational model of kiln wood drying including single board and stack level simulation, Drying Technology, Vol. 24, 2006, pp1069-1074

[27] Mujumdar, A.S., Research and development in drying: recent trends and future prospects, Drying Technology, Vol.22, 2004, pp1-26

[28] Mujumdar, A.S., An overview of innovation in industrial drying: current status and R\&D needs, Transport in Porous media, Vol.66, 2007, pp3-18

[29] Kudra, K., Mujumdar, A.S., Advanced Drying Technologies, Marcel Dekker, New York, 2001

[30] Metzger, T., Kwapinska, M., Peglow, M., Saage, G., Tsotsas, E., Modern modeling methods in drying, Transport in Porous Media, Vol.66, 2007, pp103-120 